these certificates as President of the Royal Society; he knew the licensees to be fit persons to have the respective licenses, but there was no question of individual intimate friendship.

(3) The occurrence of pain after inoculation experiments is relatively very rare, and to refer to these experiments to a popular audience as vivisections is certainly misleading it, and Mr. Coleridge must have known this. The statement that the majority of these so-called vivisections were mere pin-pricks is true.

(4) We do not complain of Mr. Coleridge's statement of what he terms the "diversion" of hospital funds to the corresponding medical schools, but we simply say that the allotment of the Prince of Waies's Hospital Fund was not influenced in any way by whether a hospital had laboratories or so-called vivisectors attached to it or not. We regard the statement that Lord Lister wilfully diverted public funds to endow vivisection as scurrilous. We entirely deny that hospital funds are, by being used for the support of medical schools, " diverted," in Mr. Coleridge's sense, from the patients. Medical schools are essential to large hospitals, and any grant made to them out of hospital funds is only in return for services rendered, although it indirectly helps the progress of medical science.

(5) The statement that Mr. Coleridge tried to make a bargain with a London hospital concerning the appointment of its staff and that the hospital declined is true; the mere wording of the reply is a matter of no importance. If Mr. Coleridge will publish the correspondence to which he refers we shall be prepared to consider it exhaustively.

(6) We entirely object to the relation between hospitals and medical schools being put before the public subscribers to the Hospital Sunday Fund in the way Mr. Coleridge suggests. If Mr. Coleridge has any scheme by which the large hospitals can receive the services of the medical profession more cheaply than they do at present he is quite justified in putting this before the public. He is, however, not justified in stigmatising grants made to medical schools as being "diverted" from the use of the sick.-EDITOR.]

\section{Vitrified Quartz}

A STUDY of the viscous properties of vitrified quartz in which I was engaged last year, and which I communicated to the Geological Congress of 1900 , revealed a degree of plasticity and molecular instability which I think justify Mr. Shenstone's reserve in pronouncing on the applicability of this substance to thermometry at high temperatures (NATURE, May 16). A few of the measurements I obtained may be of interest. I may observe that the method of observation was to stretch a quart 2 fibre (as supplied by the Cambridge Instrument Co.) in a horizontal platinum tube, which is heated by a current and clamped in the meldometer, its temperature being determined in terms of its thermal expansion. The fibre, which passes axially through the tube, is fixed at one extremity, and at the other is attached to a light pendulum, the mass of which can be increased, and which it deflects from the vertical. It is observed by two micrometers placed at some few centimetres to either extremity of the tube, so that any slip in its fixed attachment will be detected. The tube is $10 \mathrm{~cm}$. in length and $2 \mathrm{~cm}$. in diameter. Tensions are calculated in kilos. per square centimetre, and rate of elongation in centimetres per minute per unit of tension per centimetre of fibre. The different fibres used are designated $a, b, c, \& c$.

\begin{tabular}{|c|c|c|c|c|c|}
\hline Fibre & Temperature & $\begin{array}{c}\text { Duration of } \\
\text { observation in } \\
\text { minutes }\end{array}$ & Tension & \multicolumn{2}{|c|}{$\begin{array}{l}\text { Rate of stretch } \\
\text { per unit of } \\
\text { tension }\end{array}$} \\
\hline$a$ & $715^{\circ}$ & 270 & 638 & \multicolumn{2}{|c|}{$0.23+10^{-8}$} \\
\hline$b$ & $735^{\circ}$ & 95 & $135^{\circ}$ & 0.16 & , \\
\hline$l$ & $785^{\circ}$ & 165 & ,' & 0.66 & , \\
\hline$c$ & $870^{\circ}$ & 150 & $82 \cdot 2$ & $I \cdot 3$ & , \\
\hline$c$ & $915^{\circ}$ & 60 & 27.4 & $5 \cdot 3$ & " \\
\hline$c$ & ," & 50 & $54 \cdot 8$ & $4 \cdot 4$ & , \\
\hline$c$ & $920^{\circ}$ & 60 & $82 \cdot 2$ & $6 \cdot 2$ & ," \\
\hline$d$ & $915^{\circ}$ & IO & 422 & $6 \cdot 6$ & ", \\
\hline$e$ & $940^{\circ}$ & IO & 320 & $8 \cdot 5$ & , , \\
\hline$J$ & $1040^{\circ}$ & IO & , & $35^{\circ} 9$ & ", \\
\hline
\end{tabular}

This table is abridged from one giving fuller details. The fibres varied greatly in diameter and possibly somewhat in NO. I 648 , VOL. 64$]$ their viscous properties, but the results are all one way-an increasing yield with increasing temperature and a rate of stretch approximately proportional to the applied force. But this last as sertion cannot go without some reservation. At the higher temperatures, the rate of elongation was observed to diminish steadily when the observations were much prolonged. Ultimately the fibre generally breaks. When observed now between crossed nicols the fibre is found to be partially crystallised. the crystallisation extending inwards from the surface. This crystallised layer is sometimes cracked and peeled from the core beneath, the result, probably, of the very great volume-change attendant on crystallisation. The gradual diminution in rate of stretch, and a certain degree of irregularity in the results at higher temperatures, may well be due to this molecular alteration.

So far as can be inferred from the observations, the results are due to plasticity, complicated at higher temperatures by gradual crystallisation. Nor is there anything, so far as I can gather, in the least opposed to this view contained in Prof. Callendar's interesting experiments on the thermal expansion of vitreous quartz.

It will be seen from the experiments I have quoted that the viscous stretch at the lower temperatures is small in amount. With prolonged use, however, and if any considerable difference between internal and external pressure existed, thermometers would be affected by it sufficiently to necessitate frequent re. adjustment of fixed points. I find, for example, as the result of a rough estimation, that with an excess of pressure of one atmosphere within, a spherical bulb $1 \mathrm{~cm}$. in diameter and $\frac{1}{4} \mathrm{~mm}$. thick in the walls would, at $785^{\circ} \mathrm{C}$., increase in volume by $0^{\prime}$ I per cent. in about 83 hours. At $870^{\circ} \mathrm{C}$. this increase will occur in about 40 hours. At $920^{\circ} \mathrm{C}$. the same increase in volume would occur in about 8 hours if the contraction due to crystallisation, which the experiments lead us to expect, did not act the other way. The final result, after 8 hours' heating at $920^{\circ} \mathrm{C}$., would be impossible to predict.

I have more recently found that vitrifed quartz, reduced to powder and exposed over a Bunsen for 35 days in a closed unglazed porcelain crucible at a temperature just under the meltingpoint of gold $\left(1066^{\circ}\right)$ loses its sharp edges, rounding every point and angle, and simultaneously develops incipient crystallisation, which appears in the form of radial spherulitic structures, often with anisotropic centres.

Geological laboratory, Trinity College, Dublin.

\section{Statistical Investigations on Variability and Heredity.}

EARLIER appeals in your columns have met with such friendly response from scattered workers that I venture again to trouble you with an appeal for aid. I have three investigations in progress wherein help would be very welcome :-

(I) The measurement of physical and intellectual characters in pairs of brothers or sisters. Upwards of 1400 have now been observed and measured, but I have still not sufficient data. Village schools usually present a great deal of measurable material, but it is difficult to reach their teachers except through individual approach. Any of your readers who can interest their local teachers in observing and measuring pairs of children will do me a great service, and I shall be glad to send papers of instruction and a head-spanner for their use.

In examining carefully the data from nearly thirty primary schools recently returned to me, I only found two cases in which the teacher had not been fully able to use the spanner to advantage. Of course I shall be equally pleased to send papers and head-spanners to masters or mistresses in secondary schools.

(2) I shall be glad of any number of orange-tip male butterflies. They must have been caught wild and not bred, and I should like contributions from as many districts as possible. The specimens need not be very carefully set, and if the upper wings are not badly damaged they will be sure to be of use.

(3) Clutches of blackbirds' or thrushes' eggs. Each clutch must be kept perfectly separate, and certainly be from one bird. They are better unblown. If blown the hole or holes must not be at the ends. As some of your readers may have clutches they wish to preserve, but would not mind the risk of lending, I will return those so desired.

Contributions desired under (2) and (3) are for determining the intensity of homotyposis, a factor, I believe, to be at the basis of all hereditary resemblance.

University College, London, W.C., May 25.
KARL PEARSON. 